\title{
Em busca das origens desenvolvimentais dos transtornos mentais
}

\author{
Searching for the developmental origins of mental disorders
}

\author{
Guilherme V. Polanczyk* \\ * Psiquiatra da Infầncia e Adolescência, Hospital de Clínicas de Porto Alegre (HCPA), Porto Alegre, RS. Mestre e Doutor em Psiquiatria, Universidade Federal do Rio \\ Grande do Sul (UFRGS), Porto Alegre, RS. Pós-doutorando, Social, Genetic and Developmental Psychiatry Centre, Institute of Psychiatry, King's College, Londres, \\ Reino Unido, e Department of Psychology and Neuroscience, Duke University, Durham, EUA.
}

\section{Resumo}

Introdução: A psicopatologia desenvolvimental é uma disciplina que integra perspectivas epidemiológicas, sociais, genéticas, desenvolvimentais e de psicopatologia para entender as origens e o curso dos transtornos mentais. Neste artigo, são discutidos abordagens e conceitos utilizados para compreender as origens desenvolvimentais dos transtornos mentais.

Resultados: A psicopatologia desenvolvimental entende que os transtornos mentais são possíveis desfechos do processo de desenvolvimento e são dependentes de influências sociais, genéticas e ambientais. Esses diversos fatores estão inter-relacionados de diferentes formas e em diferentes níveis, exercendo um efeito dimensional. São discutidos: a) abordagens para determinar causalidade entre eventos ambientais e transtornos mentais; b) a importância de entendimento dos mecanismos biológicos através dos quais fatores ambientais e genéticos atuam; c) fatores genéticos predizendo a exposição a estressores ambientais; e d) fatores genéticos moderando o efeito de estressores ambientais

Conclusões: As origens dos transtornos mentais podem ser iluminadas por dados de estudos que utilizam enfoques e conceitos complementares e que integrem influências sociais, genéticas, ambientais e desenvolvimentais.

Descritores: Psicopatologia desenvolvimental, transtornos mentais, origens, interação gene-ambiente, correlação gene-ambiente.

\begin{abstract}
Introduction: Developmental psychopathology is a discipline that integrates epidemiological, social, genetic, developmental, and psychopathological perspectives to understand the origins and courses of mental disorders. In the present paper, theoretical concepts and approaches applied with the purpose of understanding the developmental origins of mental disorders are discussed.

Results: According to developmental psychopathology, mental disorders are possible outcomes of the developmental process that depend upon social, genetic, and environmental influences. These factors are linked in different ways and levels, exerting a dimensional effect. The following factors are addressed: a) approaches to determine a causal effect between environmental factors and mental disorders; b) the importance of understanding biological mechanisms by which environmental and genetic factors exert their effect; c) genetic factors predicting the exposure to environmental stressors; d) genetic factors moderating the effect of environmental stressors.

Conclusions: The origins of mental disorders can be clarified by data from studies that use complementary approaches and concepts, integrating social, genetic, environmental and developmental influences.
\end{abstract}

Keywords: Developmental psychopathology, mental disorders, origins, gene-environment interaction, gene-environment correlation.

\section{Correspondência:}

Guilherme V. Polanczyk, Department of Psychology and Neuroscience, Duke University, 2020 West Main Street, Suite 201, Box 104410 Durham, NC 27708, USA. Tel.: +1 919.613.6332, Fax:+1 919.684.5912. Email: gvp.ez@terra.com.br; guilherme.polanczyk@duke.edu.

Financiamento: Este trabalho é parcialmente financiado pela National Alliance for Research on Schizophrenia and Depression (NARSAD), The World's Leading Charity Dedicated to Mental Health Research, através do mecanismo 2008 Young Investigator Award.

Conflitos de interesse: Guilherme V. Polanczyk recebeu honorários de palestrante da Novartis, Brasil.

Copyright (C) Revista de Psiquiatria do Rio Grande do Sul - APRS

Recebido em 31/03/2009. Aceito em 16/04/2009. 


\section{Introdução}

A psicopatologia desenvolvimental é um campo do conhecimento dinâmico e em evolução, que tomou forma a partir do livro de Thomas Achenbach, Developmental Psychopathology $y^{1}$, publicado em 1974, e se desenvolveu principalmente a partir dos trabalhos de $\mathrm{Sroufe}^{2}, \mathrm{Cicchetti}^{3}$ e Rutter ${ }^{4}$, entre outros. A psicopatogia desenvolvimental integra perspectivas sociais, genéticas e desenvolvimentais e testa suas hipóteses através de métodos epidemiológicos e estatísticos específicos, buscando entender as origens e o curso dos transtornos mentais ${ }^{4}$.

Inicialmente, a ênfase no processo de desenvolvimento era utilizada especialmente para enteder os transtornos mentais da infância ${ }^{5}$. Com a progressão do campo, estudos passaram a mostrar que existe uma importante continuidade dos transtornos entre a infância, adolescência e idade adulta, e que grande proporção dos adultos com transtornos mentais os apresentava já na adolescência ${ }^{6}$. Assim, psiquiatras de adultos também passaram a adotar uma abordagem desenvolvimental para entender as origens dos transtornos atuais de seus pacientes ${ }^{7,8}$. De fato, resultados de pesquisas com abordagem desenvolvimental, que integram epidemiologia, genética, neuropsicologia e estudos de neuroimagem, têm mostrado grande potencial para o entendimento das origens dos transtornos mentais 9 .

Pode-se entender a psicopatologia desenvolvimental como um modelo conceitual, a partir do qual estratégias de pesquisa são desenhadas, observações são interpretadas e teorias subsequentes são geradas. Nesse sentido, a psicopatologia desenvolvimental é uma das possíveis lentes através da qual a psicopatologia pode ser vista. Neste artigo, são discutidos conceitos e abordagens utilizados por esse modelo para compreender como e por que determinados indivíduos desenvolvem transtornos mentais. Inúmeros artigos de revisão sobre diferentes aspectos dessa disciplina ${ }^{2-4,10-13}$ foram publicados, assim como um livro texto com mais de 3.000 páginas ${ }^{14}$. Portanto, o objetivo deste artigo é estimular que o leitor considere esta abordagem na sua busca individual por ferramentas para entender o processo de desenvolvimento dos transtornos mentais.

\section{Quais são os conceitos e abordagens desenvolvimentais que nos auxiliam a entender a origem dos transtornos mentais?}

Os investigadores dessa área privilegiam diferentes abordagens e conceitos, mas convergem no entendimento de que os transtornos mentais são possíveis desfechos do processo de desenvolvimento ${ }^{12}$. Convergem também no conceito de que os transtornos mentais surgem a partir de inter-relações dimensionais, complexas, em múltiplos níveis, entre características específicas do indivíduo (fatores biológicos, genéticos e psicológicos), características ambientais (cuidado parental, relacionamentos interpessoais, exposição a eventos estressores) e sociais (rede de apoio social, vizinhança, nível socioeconômico $)^{4,14}$. Quatro conceitos que norteiam abordagens desenvolvimentais merecem destaque.

Primeiro, a psicopatologia desenvolvimental assume que há continuidade no processo de desenvolvimento dos transtornos mentais, ou seja, o efeito de experiências prévias é levado adiante ao longo do desenvolvimento. Assim, a identificação de descontinuidades nesse processo caracteriza-se em uma importante oportunidade para melhor entendê- $-l^{2}$. Segundo, há uma tendência inata de os indivíduos de se adaptarem ao seu ambiente; se esse é patológico, é provável que a adaptação também o seja ${ }^{11}$. Terceiro, idade e momento do desenvolvimento são fatores fundamentais a partir dos quais todos os outros fatores devem ser entendidos ${ }^{11}$. Quarto, comportamentos mal adaptativos ou transtornos mentais devem ser interpretados frente ao contexto onde o indivíduo encontra-se inserido. Os últimos dois conceitos privilegiam a ideia de que o processo de desenvolvimento de transtornos mentais é específico, ou seja, os mecanismos causais têm resultados diferentes conforme a idade, o momento do indivíduo e o contexto familiar ou social ${ }^{4}$.

Como desfechos possíveis do processo de desenvolvimento $^{12}$, os transtornos mentais não seriam necessariamente categorias distintas, mas sim trajetórias desenvolvimentais dimensionais ${ }^{10}$. Como uma complexa malha rodoviária, em que diferentes rodovias podem levar ao mesmo local, diferentes trajetórias desenvolvimentais podem levar ao mesmo processo psicopatológico. Por outro lado, da mesma forma que as mesmas rodovias podem, ao seu final, levar a diferentes locais, as mesmas trajetórias psicopatológicas podem resultar em diferentes desfechos. Indivíduos que seguem uma determinada trajetória desenvolvimental podem passar para outra, e quanto mais cedo o desvio é feito, maior será a dificuldade para retornar ao caminho original ${ }^{3}$.

\section{Buscando fatores ambientais com efeito causal}

Entende-se que fatores de risco ambientais para os transtornos mentais atuam através de múltiplos mecanismos e níveis e usualmente estão correlacionados a uma cadeia de fatores de risco, que por sua vez podem atuar através de diversos mecanismos. $\mathrm{O}$ foco não é dado apenas nos efeitos dos fatores de risco, mas também nas suas origens, e assim pode-se entender com mais especificidade o real mecanismo através do qual atuam ${ }^{15}$.

É importante seguir uma série de estratégias para que seja demonstrada a presença de relação de causa e efeito entre fatores de risco ambientais e transtornos mentais. Primeiro, é fundamental que a relação exista em função de uma base conceitual sólida, com evidências acerca de possíveis mecanismos através dos quais os eventos operam. 
Por exemplo, existe uma série de evidências neurobiológicas que apontam o mecanismo através do qual abuso e maus tratos na infância alteram o funcionamento do eixo hipotálamo-hipófise-adrenal, podendo levar à depressão na idade adulta ${ }^{16}$. Evidências acerca de um possível mecanismo nem sempre estão disponíveis, e é frequente que a base conceitual seja revelada em função dos achados epidemiológicos. Entretanto, no momento atual do conhecimento, novos fatores de risco ambientais para os transtornos mentais têm sido infrequentemente revelados. Segundo, é fundamental mostrar uma conexão temporal consistente entre o evento estressor e o início do transtorno ${ }^{17}$. Estudos longitudinais são fundamentais para esse objetivo, e o desafio está no estudo de eventos que ocorrem cronicamente, que atuam através de diferentes mecanismos ou que mudam de intensidade ao longo do tempo. Para a elucidação da relação temporal entre ambos os fatores, é importante diferenciar se os eventos ambientais ocorreram como resultado do processo psicopatológico ou se esse iniciou anteriormente e foi causa do evento ambiental, que por sua vez pode ter exacerbado o processo psicopatológico. Como exemplo, sintomas depressivos leves podem levar à demissão de um emprego que, como consequência, pode exacerbar o processo psicopatológico levando a um episódio depressivo. Nesse caso, a demissão está correlacionada ao episódio depressivo, mas não é sua causa. Em um estudo longitudinal, se os sintomas depressivos leves anteriores não são identificados, mesmo havendo uma conexão temporal entre a demissão e o episódio depressivo, a interpretação de que existe uma relação causal entre os últimos dois eventos seria errônea. As interpretações de resultados gerados por estudos transversais apresentam maiores limitações. Terceiro, é necessário rigor na aferição de fatores de risco e desfechos através de medidas específicas e dimensionais ${ }^{15}$. No exemplo anterior, seria necessária a utilização de medidas sensíveis que identificassem os sintomas depressivos leves anteriores à demissão. Quarto, é importante contextualizar os eventos ambientais estudados. Por exemplo, demissão de um emprego pode ter significados completamente distintos para duas pessoas diferentes. Tal evento pode desencadear uma cadeia de eventos estressores, como empobrecimento, depressão, violência, atos criminosos ou pode ser o início de um novo caminho desenvolvimental caracterizado por busca de novos objetivos e conquistas.

As abordagens epidemiológicas utilizadas para demonstrar que determinado evento ambiental apresenta um efeito causal são limitadas frente à complexidade dos processos e, principalmente, frente à diversidade de variáveis confundidoras que não são levadas em consideração. A randomização é a estratégia metodológica mais apropriada para a demonstração de uma relação de causa e efeito, pois os indivíduos são alocados a uma determinada intervenção aleatoriamente. Entretanto, questões éticas óbvias não permitem a manipulação de indivíduos para que sejam expostos a eventos estressores. Assim, experimentos naturais são oportunidades ímpares para entendermos as origens dos transtornos mentais. Esses são estudos que utilizam diferenças que ocorreram naturalmente na exposição a determinado fator entre diferentes indivíduos, como a institucionalização e privação de estímulos de crianças na Romênia ${ }^{18}$, os atentados terroristas de 11 de setembro nos EUA ${ }^{19}$ ou o furacão Katrina ${ }^{20}$.

Um ensaio natural em particular buscou entender a relação entre psicopatologia e pobreza, testando se pobreza é causa de psicopatologia (social causation) ou se psicopatologia leva à pobreza (social selection) ${ }^{21}$. Uma amostra representativa de crianças de origem indígena vinha sendo avaliada anualmente para transtornos mentais. Durante o período de estudo, um cassino foi aberto na reserva indígena, e cada família que vivia na área passou a receber uma renda. Nos 4 anos seguintes à abertura do cassino, algumas famílias nunca saíram do nível de pobreza, mesmo com a nova renda; outras saíram da pobreza depois da abertura do cassino; e um terceiro grupo de famílias nunca havia sido pobre. As crianças continuaram sendo avaliadas anualmente, e observou-se que, ao final desse período, os níveis de sintomas de conduta e oposição entre as crianças de famílias que saíram da pobreza foram reduzidos para os mesmos níveis daqueles que nunca foram pobres. Entretanto, os níveis de tais sintomas entre as crianças provenientes de famílias persistentemente pobres permaneceram altos. Assim, evidenciou-se o efeito da pobreza como causa de sintomas de transtorno de conduta e oposição. Entretanto, os mecanismos através dos quais a pobreza leva à psicopatologia não foram revelados nesse estudo. Especificamente, seria bastante informativo entendermos quais os fatores intermediários que respondem ao aumento da renda e levam à redução da psicopatologia. Nesse sentido, o estudo de fatores de risco proximais ao desenvolvimento da psicopatologia, como qualidade do cuidado parental, melhores condições nutricionais ou de habitação, são mais informativos para o entendimento dos mecanismos e, consequentemente, para a elaboração de estratégias de prevenção do que fatores de risco distais, como pobreza ${ }^{22}$.

\section{Entendendo o mecanismo de ação dos agentes causais}

A psicopatologia desenvolvimental está interessada em entender os mecanismos ou processos específicos através dos quais os agentes causais atuam ${ }^{15}$. Inicialmente, é fundamental entender se um determinado fator atua por via ambiental ou genética. Em seguida, entender como o efeito ambiental "ultrapassa a pele" (get inside the skin), promovendo o desenvolvimento de transtornos mentais, e como os genes também ultrapassam a pele (get outside the skin) no sentido oposto $^{15}$, levando a comportamentos observáveis.

Um estudo recentemente publicado exemplifica a necessidade de compreendermos o mecanismo através do qual um fator supostamente ambiental atua ${ }^{23}$. Existe uma longa 
e ainda não resolvida discussão na literatura em relação ao mecanismo através do qual a exposição intraútero ao tabaco levaria à psicopatologia nas crianças. Há evidências que apontam que tal mecanismo se daria através de ação sobre o ambiente intraútero, enquanto outros estudos indicam que fumar durante a gestação é um marcador de psicopatologia materna associada a fatores genéticos que, por sua vez, são herdados pelas crianças, levando então à psicopatologia ${ }^{24}$. Rice et al. ${ }^{23}$ utilizaram uma metodologia criativa para buscar entender o mecanismo através do qual exposição intraútero ao tabaco afetava crianças nascidas através de fertilização in vitro. A contribuição da fertilização in vitro para a psicopatologia desenvolvimental reside no fato de que as crianças assim concebidas podem ser geneticamente relacionadas aos pais ou não (se houve doação de espermatozoides e/ou óvulos), sendo então possível dissociar efeitos potencialmente genéticos de efeitos sobre o ambiente intrauterino. Assim, foi comparado o efeito do tabagismo materno em relação ao peso de nascimento e comportamento antissocial entre crianças que eram e não geneticamente relacionadas às suas mães ${ }^{23}$. $\mathrm{O}$ peso de nascimento foi menor no grupo de crianças expostas ao tabaco intraútero, independentemente de serem geneticamente relacionadas ou não às suas mães. Já os níveis de comportamento antissocial foram maiores naquelas crianças expostas ao tabaco intraútero apenas quando eram geneticamente relacionadas às suas mães (tabagistas), indicando então que o efeito ambiental intraútero provocado pelo tabaco não estaria associado a comportamento antissocial nas crianças. Esse estudo mostra que exposição intraútero ao tabaco atua através de diferentes mecanismos sobre diferentes desfechos e que, no que se refere a comportamento antissocial, não atua através do ambiente intraútero. Entretanto, não podemos ter certeza se o tabagismo durante a gestação é marcador de um risco puramente genético ou se está associado a comportamentos maternos ao longo do desenvolvimento da criança, que por sua vez podem exercer efeito causal para o desenvolvimento de comportamento antissocial.

Entender os mecanismos através dos quais eventos ambientais ultrapassam a pele (get inside the skin), promovendo o desenvolvimento de transtornos mentais, é um desafio. Destacam-se, entre diversas abordagens possíveis para essa questão, três abordagens com maior sucesso até o momento. A primeira foca os efeitos neuroendócrinos dos estressores ambientais. Destaca-se a vasta literatura mostrando os efeitos neuroendócrinos de eventos estressores sobre o eixo hipotálamo-hipófise-adrenal ${ }^{16}$. A segunda foca o estudo da ação de fatores ambientais que atuam no período perinatal. Esses parecem apresentar influências persistentes ao longo do desenvolvimento (programação biológica), levando indivíduos a tomar uma ou outra trajetória desenvolvimental (plasticidade desenvolvimental) ${ }^{25}$. O quanto o ambiente ao longo do tempo estará de acordo ou não com a programação inicial estaria relacionado ao desenvolvimento de uma série de doenças físicas, como obesidade e diabete, e também de alterações hormonais relacionadas a transtornos mentais ${ }^{25}$. A terceira abordagem foca a modificação da expressão gênica provocada por estressores ambientais, através dos chamados efeitos epigenéticos ${ }^{26}$. Fatores ambientais não podem alterar a sequência gênica, mas entende-se hoje que podem alterar, ao longo do desenvolvimento, a forma como os genes são expressos, alterando o seu funcionamento e contribuindo para o desenvolvimento de transtornos mentais ${ }^{27}$.

O entendimento da ação epigenética de fatores ambientais é embasado no fato de que aproximadamente $98 \%$ do genoma humano se constitui por DNA não-codificante, localizado em regiões distantes de genes, ou seja, em regiões que não são traduzidas. O DNA não-codificante é pouco conservado entre as espécies, em comparação com o DNA codificante, que é altamente conservado. Portanto, é possível que o DNA não-codificante tenha grande influência sobre as diferenças entre as espécies. Tal influência se daria, uma vez transcrito para RNA, através da regulação da expressão dos produtos gênicos por meio de mecanismos dito epigenéticos (como fatores promotores e silenciadores da transcrição, processos alternativos de splicing, desenvelopamento das proteínas durante a translação, imprinting genômico) ${ }^{26}$. Ainda, a expressão de genes é realizada de forma seletiva em diferentes tecidos, o que é determinado por mecanismos como metilação e acetilação de histonas ${ }^{26}$.

Um estudo recente mostrou dados importantes sobre os efeitos epigenéticos do abuso na infância ${ }^{28}$. Há evidências consistentes que mostram que a expressão reduzida de receptores de glicocorticoides no hipocampo está associada a diversas psicopatologias, como depressão, esquizofrenia e suicídio ${ }^{26}$. Paralelamente, maior cuidado materno em roedores está associado a maior expressão desse receptor ${ }^{29}$. Assim, McGowan et al. ${ }^{28}$ estudaram a expressão de receptores de glicocorticoides hipocampais em cérebros de vítimas de suicídio que sofreram abuso na infância, vítimas de suicídio que não sofreram abuso e controles. A expressão dos receptores estava reduzida nas vítimas de suicídio que sofreram abuso na infância em relação aos controles, e não foi detectada diferença nos níveis de expressão entre os grupos vítimas de suicídio sem história de abuso e controles. Apesar de limitações inerentes ao desenho do estudo, tais dados fascinantes corroboram evidências anteriores em modelos animais e sugerem que alterações na expressão destes receptores está relacionada a abuso na infância. Tais dados, apesar de limitações na forma como interpretá-los, indicam um caminho bastante promissor para que possamos entender os mecanismos através dos quais eventos ambientais adversos contribuem para o desenvolvimento de transtornos mentais.

\section{Fatores genéticos predispondo à exposição a estressores ambientais}

Os genes envolvidos na suscetibilidade a transtornos psiquiátricos são constituídos por variantes alélicas comuns, 
que não alteram funções vitais ${ }^{30}$. Esses apresentam ainda um pequeno efeito de suscetibilidade no processo causal que, na maior parte das vezes, é dimensional e encontra-se em interação com complexos processos. Ainda, os genes muitas vezes apresentam um efeito indireto, determinando sensibilidade a riscos ambientais que, por sua vez, se correlacionarão com o processo psicopatológico ${ }^{11,30,31}$.

A correlação gene-ambiente é uma das possíveis interrelações entre esses fatores, referindo-se à influência genética na variabilidade dos indivíduos à exposição a tipos particulares de ambientes de risco. Ou seja, determinados comportamentos que indivíduos assumem e que se constituem em estressores ambientais são direcionados pelo genótipo do indivíduo. Tal correlação pode assumir a forma passiva, ativa ou evocativa. A correlação passiva é aquela que independe da ação do indivíduo e relaciona-se basicamente aos genes dos seus pais, que influenciam o ambiente em que o indivíduo é criado e as experiências às quais é submetido, principalmente durante os primeiros anos de vida. A forma ativa diz respeito ao efeito dos genes no comportamento do indivíduo, que determina a seleção ou o molde das experiências ambientais às quais se expõe. A forma evocativa relaciona-se ao efeito dos genes no comportamento do indivíduo que desencadeará reações nas pessoas de sua relação, moldando então suas experiências ambientais ${ }^{31}$.

\section{Fatores genéticos moderando o efeito de estressores ambientais}

Há situações em que o genótipo do indivíduo altera o efeito da exposição que um estressor ambiental provoca em relação ao desenvolvimento de transtornos mentais, ou seja, fatores genéticos atuam como moderados do efeito de eventos adversos. Nessas condições, diz-se que há interação gene-ambiente (GxE), contrapondo-se a noção tradicional de que genes e ambiente agiriam de forma aditiva, nãointerativa ${ }^{22}$. Algumas situações se constituem em indicativos da existência de uma verdadeira GxE. Evidências devem apontar para riscos substanciais de desenvolvimento de um transtorno mediados por fatores ambientais; entretanto, deve existir marcada heterogeneidade na resposta das pessoas a tais riscos, com respeito a diferenças na probabilidade do desenvolvimento do transtorno em questão ${ }^{31}$. Nesse sentido, observa-se que o mesmo estressor pode adquirir proporções devastadoras em um indivíduo, enquanto em outro pode promover o crescimento e o fortalecimento pessoal, dando origem ao conceito de resiliência. Evidências mostram que características do indivíduo prévias ao evento estressor, como temperamento e funcionamento cognitivo, que estão sob influência genética, estão associadas a resiliência, além de outros fatores que operam em diferentes momentos do tempo em relação ao evento ${ }^{11}$. Outro indicativo de possível GxE é a existência de evidências de um risco genético substancial; essa contribuição genética deve, no entanto, operar através de vias indiretas, e não através de conexão direta com uma condição particular ${ }^{31}$. Interações gene-ambiente provavelmente ocorrem quando há discordância substancial em pares de gêmeos monozigóti$\cos$ quanto à desordem em estudo ${ }^{22,31}$. Os primeiros estudos que mostraram a existência de GxE focaram na origem da depressão e do transtorno de conduta.

Em relação à depressão, é bastante claro que eventos adversos que envolvem ameaça à vida, perdas, humilhações e privações estão implicados no seu desenvolvimento ${ }^{32,33}$. Há, no entanto, marcada variabilidade da resposta de diferentes indivíduos a tais eventos. Para certos indivíduos, eventos estressantes desencadeiam um episódio depressivo, enquanto outros sujeitos submetidos a eventos tão ou mais estressantes não desenvolvem um transtorno mental ${ }^{34,35}$. Mais ainda, o peso de fatores genéticos e ambientais no desencadeamento da depressão parece sofrer influência do momento do desenvolvimento do indivíduo, com eventos estressores precoces apresentando um efeito de sensibilização ao transtorno ao longo do desenvolvimento ${ }^{36}$. Na adolescência, os fatores genéticos assumem papel central no desencadeamento da depressão, papel esse desempenhado durante a infância por estressores ambientais ${ }^{37}$. Tais achados são fortes indicativos da presença de interação entre fatores ambientais e genéticos no processo etiológico da depressão.

Os genes do sistema serotoninérgico são candidatos lógicos para o estudo dos componentes genéticos da depressão, considerando que medicações eficazes para esse transtorno agem sobre tal sistema ${ }^{38}$. O gene transportador da serotonina (5-HTT) tem recebido particular atenção, tendo sido demonstrado o seu papel como gene candidato para a depressão por estudos de associação ${ }^{38}$. Considerando os fortes indicativos de existência de GxE na etiologia desse transtorno, Caspi et al. ${ }^{39}$ estudaram o papel moderador de um polimorfismo funcional na região promotora do 5-HTT sobre eventos de vida estressantes no desenvolvimento de depressão. Aqueles indivíduos com alelo curto no polimorfismo 5-HTTLPR apresentaram um impacto significativamente maior dos eventos estressores do que os indivíduos homozigotos para o alelo longo.

Em relação ao transtorno de conduta, tal transtorno apresenta coeficiente de herdabilidade (proporção da variança total de uma característica explicada por fatores genéticos) de aproximadamente $50 \%$, havendo discordância substancial entre gêmeos monozigóticos. Fatores de risco ambientais apresentam importante influência no seu desenvolvimento, havendo marcada heterogeneidade quanto à resposta aos estressores entre os indivíduos. Além disso, o efeito dos estressores parece ser mais marcado naquelas crianças e adolescentes em risco genético.

A partir de tais evidências, Caspi et al. ${ }^{40}$ avaliaram o efeito da interação entre um polimorfismo funcional na região promotora do gene para a enzima monoamino oxidase 
A (MAO-A) e situações de maus-tratos na infância sobre o desenvolvimento de comportamentos antissociais na vida adulta. Dados consistentes apontam para a relação da MAOA com agressividade, tanto em modelos animais como em humanos. Essa enzima metaboliza neurotransmissores como noradrenalina, serotonina e dopamina, sendo que sua atividade reduzida disporia o organismo a uma hiperreatividade neural a ameaças. Maus-tratos na infância é um fator de risco conhecido e bem estudado para comportamento antissocial na vida adulta. Entretanto, uma proporção importante de crianças que sofreram maus-tratos na infância não apresenta comportamento antissocial ao longo do seu desenvolvimento, o que levanta a hipótese de que influências genéticas possam apresentar efeito moderador sobre tal estressor. Os resultados do estudo mostraram que a atividade da MAO-A não apresentou efeito principal sobre o desenvolvimento de comportamento antissocial ${ }^{40}$. Já maus-tratos na infância apresentou efeito significativo sobre o desfecho, e tal efeito foi moderado pelo gene da MAO- $\mathrm{A}^{40}$. Ou seja, indivíduos com baixa atividade enzimática que sofreram maus-tratos na infância apresentaram maior chance de desenvolver transtorno de conduta, de serem condenados por crimes graves e de apresentarem maiores pontuações nas escalas de comportamento violento e antissocial do que aqueles que sofreram maus-tratos mas não apresentavam baixa atividade enzimática ${ }^{40}$.

Os achados desses estudos apontaram para um novo caminho de investigação, e diversos estudos, abordando diferentes fatores de risco, genes e desfechos, vêm sendo publicados desde então ${ }^{41}$. Isso se deve principalmente ao potencial preventivo que o desvendamento de quais fatores genéticos tornariam as pessoas mais sensíveis ou resistentes a desenvolver um transtorno mental, quando expostos a fatores adversos, apresenta. Entretanto, para alcançarmos com sucesso essa meta, é importante que sejam identificadas interações reais, com um significado biológico plausível, e não apenas interações estatísticas. Para tanto, além do estudo do transtorno mental em questão, parece ser fundamental entender o efeito do evento estressor de interesse em indivíduos sem psicopatologia (do ponto de vista fenotípico e neurobiológico), assim como o estudo de modelos animais e o entendimento da relevância funcional dos polimorfismos de interesse ${ }^{42}$.

\section{Perspectivas futuras}

A complexidade e a especificidade dos processos que levam ao desenvolvimento de transtornos mentais desafiam a nossa capacidade de entendê-los em detalhes. O desenvolvimento de estudos longitudinais, que acompanham indivíduos ao longo do tempo, desde os momentos iniciais do seu desenvolvimento, é um caminho promissor ${ }^{43}$. De fato, terá início em 2010 o National Children's Study, um estudo longitudinal que seguirá mais de 100.000 crianças nos EUA, desde antes da concepção até os 20 anos de idade $^{44}$. Considerando o poder estatístico e a complexidade das avaliações que serão realizadas neste estudo ${ }^{13}$, existe uma grande expectativa quanto aos resultados que serão gerados nas próximas décadas.

O desenvolvimento de novas técnicas de análise genética, principalmente a técnica de análise em larga escala (microarrays), poderá proporcionar uma visão global de padrões de expressão gênica. Centenas de genes poderão ser avaliados ao mesmo tempo e o risco genético de determinado indivíduo poderá ser predito. Conhecendo a magnitude do risco, será possível explorar questões desenvolvimentais ${ }^{27}$. Não é claro, no entanto, se esse fantástico arsenal produzirá conhecimentos suficientemente robustos que sejam passíveis de tradução para intervenções clínicas ${ }^{45}$. Em paralelo, o desenvolvimento de novas ferramentas estatísticas, como a análise de trajetórias desenvolvimentais através da utilização de modelagem de variáveis latentes ${ }^{46,47}$ ou a análise através de múltiplos níveis ${ }^{48}$, também possibilitará que questões mais complexas possam ser entendidas. Entretanto, todas essas técnicas terão sucesso apenas se a avaliação dos fatores ambientais for realizada de forma refinada, com rigor metodológico. Está claro que a forma como as variáveis ambientais é conceitualizada e medida influencia de forma significativa os resultados encontra$\operatorname{dos}^{49}$. Assim, a avaliação de estressores ambientais deve estar amparada em sólidas bases conceituais.

\section{Conclusões}

A psicopatologia desenvolvimental, como uma lente para olharmos e entendermos os transtornos mentais, minimiza e privilegia determinados aspectos. Cabe a cada investigador avaliar criticamente a utilização desse modelo conceitual. A psicopatologia desenvolvimental refuta a ideia de que fatores de risco atuam de forma isolada e não se satisfaz apenas com a identificação de associações ou correlações. Para que possamos traduzir o conhecimento gerado em benefícios para a população, precisamos entender os mecanismos através dos quais fatores de risco levam ao desenvolvimento de transtornos mentais. Para tanto, estudos com abordagens complementares, que integrem diferentes conceitos e utilizem desenhos proporcionados por eventos naturais, têm um grande potencial para a elucidação das origens desenvolvimentais dos transtornos mentais.

\section{Referências}

1. Achenbach TM. Developmental psychopathology. New York: Wiley; 1974.

2. Sroufe LA, Rutter M. The domain of developmental psychopathology. Child Dev. 1984;55(1):17-29.

3. Cicchetti D, Sroufe LA. The past as prologue to the future: the times, they've been a-changin'. Dev Psychopathol. 2000;12(3):255-64.

4. Rutter M, Sroufe LA. Developmental psychopathology: concepts and challenges. Dev Psychopathol. 2000;12(3):265-96. 
5. Rutter M. "Project Future": the way forward for child psychiatry? J Am Acad Child Psychiatry. 1984;23(5):577-81.

6. Kim-Cohen J, Caspi A, Moffitt TE, Harrington H, Milne BJ, Poulton R. Prior juvenile diagnoses in adults with mental disorder: developmental follow-back of a prospective-longitudinal cohort. Arch Gen Psychiatry. 2003;60(7):709-17.

7. Goldstein BI, Levitt AJ. Further evidence for a developmental subtype of bipolar disorder defined by age at onset: results from the national epidemiologic survey on alcohol and related conditions. Am J Psychiatry. 2006;163(9):1633-6.

8. Reiman EM, Chen K, Alexander GE, Caselli RJ, Bandy D, Osborne D, et al. Functional brain abnormalities in young adults at genetic risk for late-onset Alzheimer's dementia. Proc Natl Acad Sci U S A. 2004;101(1):284-9.

9. Meyer-Lindenberg A, Weinberger DR. Intermediate phenotypes and genetic mechanisms of psychiatric disorders. Nat Rev Neurosci. 2006;7(10):818-27.

10. Hudziak JJ, Achenbach TM, Althoff RR, Pine DS. A dimensional approach to developmental psychopathology. Int J Methods Psychiatr Res. 2007;16 Suppl 1:S16-23.

11. Rutter M. The interplay of nature, nurture, and developmental influences: the challenge ahead for mental health. Arch Gen Psychiatry. 2002;59(11):996-1000.

12. Sroufe LA. Psychopathology as an outcome of development. Dev Psychopathol. 1997;9(2):251-68

13. Swanson JD, Wadhwa PM. Developmental origins of child mental health disorders. J Child Psychol Psychiatry. 2008;49(10):1009-19.

14. Cicchetti D, Cohen DJ. Developmental Psychopathology. New York: John Wiley and Sons; 2006

15. Rutter M. Understanding and testing risk mechanisms for mental disorders. J Child Psychol Psychiatry. 2009;50(1-2):44-52.

16. Gunnar M, Quevedo K. The neurobiology of stress and development. Annu Rev Psychol. 2007;58:145-73.

17. Rutter M. Epidemiological methods to tackle causal questions. Int J Epidemiol. 2009;38(1):3-6.

18. Rutter M, Kreppner J, Croft C, Murin M, Colvert E, Beckett C, et al. Early adolescent outcomes of institutionally deprived and non-deprived adoptees. III. Quasi-autism. J Child Psychol Psychiatry. 2007;48(12):1200-7.

19. Hoven CW, Duarte CS, Lucas CP, Wu P, Mandell DJ, Goodwin RD, et al. Psychopathology among New York city public school children 6 months after September 11. Arch Gen Psychiatry. 2005;62(5):545-52.

20. Galea S, Brewin CR, Gruber M, Jones RT, King DW, King LA, et al. Exposure to hurricane-related stressors and mental illness after Hurricane Katrina. Arch Gen Psychiatry. 2007;64(12):1427-34.

21. Costello EJ, Compton SN, Keeler G, Angold A. Relationships between poverty and psychopathology: a natural experiment. JAMA. 2003;290(15):2023-9.

22. Moffitt TE, Caspi A, Rutter M. Strategy for investigating interactions between measured genes and measured environments. Arch Gen Psychiatry. 2005;62(5):473-81.

23. Rice F, Harold GT, Boivin J, Hay DF, van den Bree M, Thapar A. Disentangling prenatal and inherited influences in humans with an experimental design. Proc Natl Acad Sci U S A. 2009;106(7):2464-7.

24. Ernst M, Moolchan ET, Robinson ML. Behavioral and neural consequences of prenatal exposure to nicotine. J Am Acad Child Adolesc Psychiatry. 2001;40(6):630-41.

25. Gluckman PD, Hanson MA, Cooper C, Thornburg KL. Effect of in uterus and earlylife conditions on adult health and disease. N Engl J Med. 2008;359(1):61-73.

26. Sweatt JD. Experience-dependent epigenetic modifications in the central nervous system. Biol Psychiatry. 2009;65(3):191-7.

27. Plomin R, Davis OS. The future of genetics in psychology and psychiatry: microarrays, genome-wide association, and non-coding RNA. J Child Psychol Psychiatry. 2009;50(1-2):63-71.
28. McGowan PO, Sasaki A, D’Alessio AC, Dymov S, Labonte B, Szyf M, et al. Epigenetic regulation of the glucocorticoid receptor in human brain associates with childhood abuse. Nat Neurosci. 2009;12(3):342-8

29. Weaver IC, Cervoni N, Champagne FA, D'Alessio AC, Sharma S, Seckl JR, et al. Epigenetic programming by maternal behavior. Nat Neurosci. 2004;7(8):847-54.

30. Kendler KS. "A gene for...": the nature of gene action in psychiatric disorders. Am J Psychiatry. 2005;162(7):1243-52

31. Rutter M, Moffitt TE, Caspi A. Gene-environment interplay and psychopathology: multiple varieties but real effects. J Child Psychol Psychiatry. 2006;47(3-4):226-61.

32. Kendler KS, Kessler R, Walters E, Maclean C, Neale N, Heath A, et al. Stressful life events, genetic liability, and onset of an episode of major depression in women. Am J Psychiatry. 1995;152:833-42.

33. Kessler RC, Davis CG, Kendler KS. Childhood adversity and adult psychiatric disorder in the US National Comorbidity Survey. Psychol Med. 1997;27(5):1101-19.

34. Silberg J, Rutter M, Neale M, Eaves L. Genetic moderation of environmental risk for depression and anxiety in adolescent girls. Br J Psychiatry. 2001;179:116-21.

35. Eaves L, Silberg J, Erkanli A. Resolving multiple epigenetic pathways to adolescent depression. J Child Psychol Psychiatry. 2003;44(7):1006-14.

36. Kendler KS, Kuhn JW, Prescott CA. Childhood sexual abuse, stressful life events and risk for major depression in women. Psychol Med. 2004;34(8):1475-82.

37. Scourfield J, Rice F, Thapar A, Harold GT, Martin N, McGuffin P. Depressive symptoms in children and adolescents: changing aetiological influences with development. J Child Psychol Psychiatry. 2003;44(7):968-76.

38. Anguelova $\mathrm{M}$, Benkelfat $\mathrm{C}$, Turecki $\mathrm{G}$. A systematic review of association studies investigating genes coding for serotonin receptors and the serotonin transporter: I. Affective disorders. Mol Psychiatry. 2003;8(6):574-91.

39. Caspi A, Sugden K, Moffitt TE, Taylor A, Craig IW, Harrington H, et al. Influence of life stress on depression: moderation by a polymorphism in the 5-HTT gene. Science. 2003;301(5631):386-9.

40. Caspi A, McClay J, Moffitt TE, Mill J, Martin J, Craig IW, et al. Role of genotype in the cycle of violence in maltreated children. Science. 2002;297(5582):851-4.

41. Caspi A, Moffitt TE. Gene-environment interactions in psychiatry: joining forces with neuroscience. Nat Rev Neurosci. 2006;7(7):583-90.

42. Rutter M. Biological implications of gene-environment interaction. J Abnorm Child Psychol. 2008;36(7):969-75.

43. Robertson SP, Poulton R. Longitudinal studies of gene-environment interaction in common diseases_-good value for money? Novartis Found Symp. 2008;293:12837; discussion 138-42, 181-3.

44. Collins FS. The case for a US prospective cohort study of genes and environment. Nature. 2004;429(6990):475-7.

45. Rutter M, Plomin R. Pathways from science findings to health benefits. Psychol Med. 2009;39(4):529-42.

46. Muthen B, Muthen LK. Integrating person-centered and variable-centered analyses: growth mixture modeling with latent trajectory classes. Alcohol Clin Exp Res. 2000;24(6):882-91.

47. Nagin DS, Tremblay RE. Analyzing developmental trajectories of distinct but related behaviors: a group-based method. Psychol Methods. 2001;6(1):18-34

48. Von KorffM, Koepsell T, Curry S, Diehr P. Multi-level analysis in epidemiologic research on health behaviors and outcomes. Am J Epidemiol. 1992;135(10):1077-82.

49. Polanczyk G, Caspi A, Williams B, Price TS, Danese A, Sugden K, et al. Protective effect of CRHR1 gene variants on the development of adult depression following childhood maltreatment: Replication and extension. Arch Gen Psychiatry. 2009; no prelo. 